\title{
MODELING OF RECENT VOLCANIC EPISODES AT PHLEGREAN FIELDS (ITALY): GEOCHEMICAL VARIATIONS AND GROUND DEFORMATION
}

\author{
Micol Todesco ${ }^{1}$, Jonny Rutqvist ${ }^{2}$, Giovanni Chiodini ${ }^{3},{\text { Karsten } \text { Pruess }^{2} \text {, Curtis M. Oldenburg }}^{2}$ \\ ${ }^{1}$ INGV, Dip. Scienze della Terra e Geo-Ambientali \\ P.zza P.ta San Donato,1, I-40126 Bologna (Italy) \\ E-mail: todesco@geomin.unibo.it \\ ${ }^{2}$ Earth Sciences Division \\ Lawrence Berkeley National Laboratory, Berkeley, CA 94720 (USA) \\ ${ }^{3} \mathrm{INGV}$, Osservatorio Vesuviano \\ via Diocleziano, 328 -I-80124 Napoli (Italy)
}

\begin{abstract}
Phlegrean Fields is an active caldera structure, located at the periphery of Naples (Italy). After the last eruptive event (the Monte Nuovo eruption, in 1538), periodic episodes of unrest characterize the evolution of this volcanic district, involving seismic activity and slow ground motion (bradyseism). During unrest episodes, there have been significant changes in the composition of hydrothermal fluids discharged at La Solfatara fumarolic field. These unrest phenomena result from complex interaction between the magma chamber, hydrothermal fluid circulation, and country rocks undergoing thermal and mechanical stresses. Understanding the mechanism driving bradyseismic activity and unravelling the relation between ground deformation and hydrothermal fluid circulation are necessary steps toward developing an effective hazard assessment in a densely populated area such as Phlegrean Fields. In this work, we present some results of numerical modeling of both the hydrothermal fluid circulation at La Solfatara, and of its effects on rock deformation. Modeling results show that periods of intensified magmatic degassing explain many features of the recent unrest crises at Phlegrean Fields.
\end{abstract}




\section{INTRODUCTION}

Coupling between thermal gradients, hydrologic flows, and mechanical deformation of rocks has been widely recognized and complex thermo-hydro-mechanical (THM) interactions are known to occur in many geological contexts and applications (Tsang, 1999). Examples of application in which coupled THM processes play a relevant role include the disposal of nuclear waste in geological media and the underground injection and storage of carbon dioxide (Rutqvist et al., 2002). In addition, any development involving fluid injection or withdrawal (such as groundwater, oil, or natural gas extraction) is expected to bring along some degree of deformation of the geological formation involved. The case of the Wairakei geothermal field, in New Zealand, represents a very good example of the remarkable interaction between fluid extraction and ground deformation. Data collected over 45 years of monitoring activity have shown that a maximum ground subsidence of $14 \mathrm{~m}$ was produced between 1950 and 1997, as a result of the field development for power generation (Allis, 2000). As a consequence of fluid extraction, a pressure drawdown of ca. 2.5 $\mathrm{MPa}$ was generated at depth and led to a maximum subsidence rate of $480 \mathrm{~mm} / \mathrm{yr}$, during the mid-1970s. Modelling of drainage and compaction of low permeability sediments was carried out to investigate future trend that could result from future production (Allis and Zhan, 2000). The model accounts for a 1-D, single phase (liquid) flow through a compressible mudstone and showed how differential subsidence is likely related to differences in mudstone compressibility at different location.

The slow ground motion (bradyseism) characterizing many calderas around the world (Dzurisin and Yamashita, 1987; Newhall and Dzurisin, 1988; Dzurisin et al., 1990; 1999; Dvorak and Gasparini, 1991; Marshall et al., 1997; Wicks et al., 1998) is another important and widespread phenomenon where coupled THM processes play an important role. The Phlegrean Field caldera, Italy (Figure 1), is a good example of this phenomenon, for which detailed data on both ground deformation and fluid geochemistry are available. Subsidence affects this caldera since Roman times (Dvorak and Mastrolorenzo, 1991), and it is periodically interrupted by short-lasting uplift phases. One of these episodes, totaling a maximum vertical displacement of $7 \mathrm{~m}$, preceded the onset of the last eruption, at Monte Nuovo, in 1538 (Dvorak and Gasparini, 1991). Two other big events occurred recently, in 1969 and 1982, each one accompanied by seismic activity and leading to a vertical displacement of about 2 m (Casertano et al., 1976; Barberi et al., 1984). In this case, luckily, a renewal of eruptive activity did not follow. Since 1985, a slow, aseismic subsidence has been observed, only interrupted by three very small uplift. Each event, since 1982 
has been accompanied by notable changes in the composition of fumarolic gases (Cioni et al., 1984; Barberi et al., 1984; Tedesco and Scarsi, 1999).

There are several published studies that describe these recent bradyseismic crises, especially regarding the remarkable ground deformation observed and its possible origin. Even though early authors already recognized the potential role of hydrothermal fluid circulation in these events (Olivieri del Castillo and Quagliariello, 1969; Casertano et al., 1976), modelling efforts mostly focused on the mechanical aspects at first, describing the bradyseismic phenomenon as the result of a pressure build-up inside a magma chamber (Caputo, 1976; Casertano et al., 1976; Corrado et al., 1976; Berrino et al., 1984; Bonafede et al., 1986; Bianchi et al., 1987). Many of these authors describe the magma chamber as a pressure source embedded in a homogeneous half space, with elastic or visco-elastic properties. Later on, the effects of structural discontinuities in controlling both the magnitude and the spatial extent of ground deformation were introduced (De Natale and Pingue, 1993; De Natale et al., 1997). The role of heating and expansion of hydrothermal fluids during a bradyseismic event was accounted for in a physical model by Bonafede (1991), and later on by other authors who recognized the importance of hydrothermal circulation not only to explain some of the observed ground uplift, but also to account for the following subsidence phase (Gaeta et al., 1998; Orsi et al., 1999; De Natale et al., 2001; Castagnolo et al., 2001). These works provided important insights on recent crises, but are commonly based on simple descriptions of the fluid dynamics, usually accounting for a steady flow of a single-phase fluid (liquid water), of constant properties.

A more realistic description of the hydrothermal fluid circulation at La Solfatara was performed recently (Todesco et al., 2003a; Chiodini et al., 2003), and could capture several features characterizing this hydrothermal system and its evolution. Todesco et al. (2003a) successfully simulated the present system conditions, consistently using a conceptual model that was independently developed based on geochemical data (Chiodini and Marini, 1998). Chiodini et al. (2003) focused on the interpretation and modeling of the geochemical variations observed during bradyseismic crises. These two papers provided a more accurate description of the hydrothermal fluid circulation, but they in turn neglect the deformation of the solid porous rock. A further step forward was then performed, to couple fluid-dynamics of hydrothermal circulation to a mechanical analysis of the porous media (Todesco et al., 2003b). In that work, the coupled TOUGH-FLAC simulator (Rutqvist et al., 2002) was applied to study the mechanical and hydrothermal effects of the injection of deep fluids into a hot and shallow hydrothermal system. 
Results showed that a short period (2 years) of higher inflow of deep fluids can generate significant amount of rock deformation, and also trigger changes in the composition of the dry gas zone feeding the fumaroles.

The present paper represents a further extension of both these lines of research. In the first part of the paper we only simulate the hydrothermal circulation, investigating the role of deep fluid composition, duration of system crises and fluid injection rate during the system crises; in the second part, further results of the coupled thermo-hydro-mechanical modeling are presented, in which we focused on the role of the duration of high injection rate periods (HIRP) and on the effects of a gradual reduction of the injection rate at the end of the crisis.

Results confirm that an important correlation exists between deformation and chemical variations, and show that the multi-phase, multi-component nature of the processes involved plays an important role in determining the system evolution.

\section{HYDROTHERMAL CIRCULATION}

Simulations of the hydrothermal fluid circulation were performed with the TOUGH2 simulator (Pruess, 1991), accounting for the coupled transport of heat and multi-phase fluids through a porous medium. In the present application, fluids are water and carbon dioxide, and the porous matrix is assumed to be homogeneous and isotropic. Simulations take full advantage of the simple geometry of the natural system, and were run on a 2-D, cylindrical domain (Figure 2). As in Todesco et al. (2003a), initial conditions were calculated by simulating a prolonged (4000 year) injection of hot $\left(350^{\circ} \mathrm{C}\right)$ water and carbon dioxide at the base of the hydrothermal system. The deep fluid source has the same size as La Solfatara crater, and the composition of the injected mixture $\left(\mathrm{CO}_{2} / \mathrm{H}_{2} \mathrm{O}\right.$ volume ratio $\left.=0.17 \mathrm{vol}\right)$ matches the composition of the fumarolic gases at the beginning of 1983. Injection rates (1000 ton/day of $\mathrm{CO}_{2}$ and 2400 ton/day of $\mathrm{H}_{2} \mathrm{O}$ ) were arbitrarily chosen, and match (to within an order of magnitude) the recent estimate of diffuse $\mathrm{CO}_{2}$ degassing through the bare soil at La Solfatara (Chiodini et al., 2001; Todesco et al., 2003a). Prolonged heating leads to the development of a hot two-phase plume, within which a shallow single-phase gas region forms (Figure 3), whose existence and physical conditions match the prediction of the geochemical model proposed for La Solfatara (Chiodini and Marini, 1998). This single phase gas region was interpreted as the source feeding the active fumarolic field at La Solfatara. Its average composition is taken here as representative of fumarolic emissions. Taking these results as a baseline condition, three different simulations were run 
(Table 1), each characterized by four periods of higher injection rate (HIRP), as in Chiodini et al. (2003). The aim of the simulations presented here was to establish whether an increase in carbon dioxide at the source is necessary to achieve the observed compositional variability. To this purpose, the injection rate of deep fluids was increased here by a factor of 3,5 and 7 times, respectively, while both the injection fluid temperature $\left(350^{\circ} \mathrm{C}\right)$ and composition $\left(\mathrm{CO}_{2} / \mathrm{H}_{2} \mathrm{O}=0.17 \mathrm{vol}\right)$ were kept unchanged.

Figure 4 shows the effects of the four imposed HIRP on the average composition of the singlephase gas region, expressed as $\mathrm{CO}_{2} / \mathrm{H}_{2} \mathrm{O}$ vol ratio, for each of the three simulations. Measured composition are also shown for comparison. When the fluid injection rate is increased, the pore pressure near the source also increases, leading to a certain degree of vapor condensation. When the injection rate is reduced again, pore pressures quickly decline, and water boiling takes place where larger amount of fluid decompression occurs. These phase changes are responsible for significant temperature variations, associated with latent heat effects. As it will be shown in the second part of the paper, these temperature variations play an important role in rock deformation. At the same time, water phase changes affect gas composition, which becomes depleted or enriched in water vapor, according to the current conditions. These changes initially involve the deepest portion of the domain, near the fluid source, where pressure variations are more dramatic. However, as the simulation proceeds, the pressure and temperature perturbations progressively involve shallower portions of the domain. Eventually, the single-phase gas region is affected and in each case, a peak in the $\mathrm{CO}_{2} / \mathrm{H}_{2} \mathrm{O}$ ratio is reached some time after the end of the HIRP (Figure 4). The amount of $\mathrm{CO}_{2}$ enrichment depends on the fluid injection rate and on the HIRP duration. Higher $\mathrm{CO}_{2} / \mathrm{H}_{2} \mathrm{O}$ values are followed by a faster decline when the injection rate is reduced again. As the number of HIRPs increases, their effects in terms of composition of the shallow single-phase gas region tend to accumulate, as the fluids injected earlier ascend and reach shallower depth, while new injections occur. The combined effect of multiple HIRPs becomes particularly evident when the injection rate is higher: in simulation $7 \mathrm{x}$, the compositional peak after the $3^{\text {rd }}$ HIRP is almost as high as the previous one, which was induced by a longer HIRP. The same effect is observed also in the other simulations after the following (and even shorter) HIRP. Multiple HIRPs also affect the minimum values of the gas ratio that are reached after the fluid injection rate has been reduced. Initially, these minimum values are similar for each simulation (and close to the initial composition of the single-phase gas region), but after the $3^{\text {rd }}$ HIRP the gas compositions calculated in the three considered cases differ, with 
greater $\mathrm{CO}_{2}$ depletion obtained for the Simulation $3 \mathrm{x}$, which has with a smaller increment in the HIRP fluid injection rate.

Even if all simulations in Figure 4 produced significant changes in gas composition, none of the plotted curves provides a good match with observed data at all times. To improve data fitting more simulations were performed changing the length of the HIRP, and always keeping the composition of injected mixture unchanged. The best result is shown in Figure 5, and was achieved increasing the HIRP injection rate 5 times above the baseline value and by assigning slightly longer HIRP (Simulation $5 \mathrm{x}_{\mathrm{HIRP}}$ ).

An additional simulation was performed to evaluate the role of compositional changes of the injected fluid (Figure 6). Simulation 1x-C was run without increasing the fluid injection rate at the source, but only changing the relative water- $\mathrm{CO}_{2}$ ratio from 0.17 to 0.30 vol, during the HIRPs. The duration of HIRPs for this case was the same as was chosen for simulated $3 \mathrm{x}, 5 \mathrm{x}$ and 7x (Table 1). As Figure 6 shows, the single-phase gas region in this case undergoes changes in its average composition, but the amplitude of these variations is much lower than the observed changes in gas composition.

\section{COUPLED THERMO-HYDRO-MECHANICAL SIMULATIONS}

The coupled TOUGH-FLAC simulator applied here links the capabilities of the TOUGH2 geothermal simulator (Pruess, 1991) with the geomechanical analysis of rock and soil performed with FLAC3D, a commercial code for rock mechanics (Itasca Consulting Group Inc., 1997). Both codes are fully described elsewhere, as is their coupling (Rutqvist et al., 2002). Briefly, FLAC3D is an explicit finite difference program applied here to describe the coupled thermomechanical behaviour of a continuous elastic medium. At this time, only a one-way coupling was considered, in which the pore pressure and temperature fields, calculated with TOUGH2, are fed to FLAC3D, which in turn calculates the stress and strain distribution arising from changes in pressure and temperature (Todesco et al., 2003b). The coupled TOUGH-FLAC model allowed us to study the mechanical effects associated with periods of intensified magmatic degassing. As in the previous section, system unrest is simulated as a sudden increase in fluid injection rate at the deep source, followed by a longer period during which the injection rate is reduced to a background value. In all coupled simulations the composition of injected fluids does not change and only one single HIRP is imposed at the beginning of the simulation. Previous simulations addressed the role of fluid injection rate during HIRPs, and of rock elastic properties (Todesco et 
al., 2003b). Simulations presented here describe the effects of a gradual reduction of the injection rate during the HIRP, and the role of a 10-year-long HIRP (Table 2). Injection rates and fluid composition are reported in Table 2 and are consistent with those in Todesco et al. (2003b). The 3-D computational domain and boundary conditions are shown in Figure 7. In the following, a brief description of the hydrothermal circulation in each case is followed by the analysis of the mechanical effects. As mentioned above, when the injection rate is higher, pore pressure also increases and leads to water condensation. The source region undergoes significant heating resulting from the release of latent heat during condensation. This pressure and temperature perturbation tends to rise toward shallower levels, as fluids slowly propagate from the source outward.

System conditions at the end of a 2 year long period of high injection can be conveniently described in terms of pressure, temperature, gas fraction and composition (Simulation 10x; Figure 8). When the injection rate is reduced, sudden decompression takes place in the source region. There, water can boil, subtracting latent heat and increasing the gas saturation. Gas composition also changes thanks to the increasing the amount of water vapor. Meanwhile, the overpressure generated during the HIRP dissipates, as the heated fluids continue to rise (Todesco et al., 2003b). System conditions 5 years after the injection rate has been reduced are shown in Figure 9.

The evolution of the hydrothermal system is different if, after 2 years, the injection rate is not suddenly reduced, but it gradually declines during the following 3 years (Simulation 10x-g; Figure 10). In this case, system conditions at the end of the HIRP are characterized by higher pressure and temperature. At shallow depth, the gas fraction at the base of the single-phase gas region is lower and the gas phase is enriched in carbon dioxide. Five years after the end of the HIRP (i.e.: after 10 years of simulation), system conditions are similar to those obtained with a sharp reduction of injection rate (Figure 9), but some differences exist both in pressure and temperature distribution, and lead to a different phase distribution and gas composition. As will be shown later, such different temperature and pressure distributions will result in a different evolution of the ground deformation.

Another simulation was run considering a longer HIRP, lasting 10 years (Simulation 10x-1; Figure 11). The fluid injection rate is again 10 times higher during the HIRP. To compare the effects of such a long period of high injection rate with previous results, Figure 11 illustrates the system conditions 5 years after the injection rate has been reduced (i.e.: after 15 years of 
simulation). In this case, the longer HIRP resulted in significant increases of both pressure and temperature. As a consequence, when the injection rate is relieved a much more evident decompression occurs at depth, and extensive boiling strongly reduces the $\mathrm{CO}_{2}$ mass fraction within the gas phase. In addition to the different pressure and temperature distribution, the most notable feature of this simulation is the disappearance of the single-phase gas region. This happens because the pressure wave, caused by the higher fluid injection rate, can propagate upward for a long enough time to reach shallow depths, where the single-phase gas region is located.

This generates enough condensation to turn the single-phase gas reservoir into a two-phase region. Condensation does not affect, however, all the water in the reservoir, as half of the gas at shallow depth still is water vapor, due to the high temperature. The different system conditions presented above result in different evolution of the ground deformation.

The mechanical displacement induced by the changing pressure and temperature was calculated in a stress-strain analysis using the FLAC3D part of the TOUGH-FLAC simulator. The mechanical model was first executed to mechanical equilibrium for the initial temperature and pressure distribution resulting from the background injection. The additional deformation created by the changes in pressure and temperature during an HIRP are then calculated at selected times. These deformations are the results of effective stress changes (as fluid pressure changes) and a thermal rock expansion (as rock temperature changes). The combined impact of effective stress changes and thermal expansion results in rock-mass deformations that can be observed as movements of the ground surface. Figure 12 shows the vertical ground displacement, on a XZ plane, calculated after 2 years for simulation 10x. System conditions and ground deformation at this time, are the same in all the simulations described above. The maximum vertical displacement is $0.64 \mathrm{~m}$ and it is reached at a depth of $1100 \mathrm{~m}$. Figure 12 also shows how such deformation evolves for Simulation 10x, 5 years after the injection rate is sharply reduced (Simulation 10x).

If the injection rate is gradually reduced, the maximum ground deformation is again attained at the end of the HIRP, which in this case is after 5 years of simulation. Figure 13 shows the distribution of the vertical ground displacement at the end of the HIRP (a) and 5 years after (b). Because of the longer duration of the HIRP, the maximum deformation is slightly higher $(0.68$ $\mathrm{m})$, it is achieved later, and at a shallower depth $(800 \mathrm{~m})$. Once the injection rate is reduced, the vertical displacement also declines (Figure 13b). The region affected becomes larger and 
shallower. A more significant ground deformation is calculated when the HIRP lasts 10 years (Figure 14). During such a long period, the maximum vertical displacement not only reaches very high values $(1.45 \mathrm{~m})$ but also involves a wide and very shallow region. When the injection rate is finally reduced, both decompression and temperature drop are fast, and within 5 years the rock deformation becomes negligible (Figure 14b). The maximum vertical uplift experienced at the surface in all of these simulations is shown in Figure 15 as a function of time. In each simulation, the maximum deformation is always achieved at the end of the HIRP.

We only expected to reproduce a fraction of the observed ground deformation, as we only model the shallowest portion of the hydrothermal system, and hence we neglect the contribution arising from heating and pressure changes affecting the volcanic system at greater depths.

If the HIRPs last 2 years only, and then injection rate is sharply reduced, the maximum vertical displacement achieved at the surface is $0.31 \mathrm{~m}$. Afterwards subsidence begins at a slower rate. This temporal evolution well represents the observed trend of ground deformation, and even though the absolute value of vertical ground displacement is lower, the rate of uplift and subsequent subsidence match the observation, as shown in Figure 16 (Todesco et al., 2003b).

When the injection rate is not suddenly reduced, but diminishes gradually during the following 3 years, vertical displacement continues to rise, even though at a progressively smaller rate (Figure 15). Only when injection rate is fixed again at its background value, the vertical displacement begins to gradually decline. Subsidence, in this case, is somewhat faster than for simulation 10x. If the HIRP lasts 10 years, vertical displacement continues to rise for the entire period, to a maximum value of about $1 \mathrm{~m}$, and then quickly drops when the injection rate is reduced. In this case, the calculated subsidence reaches the same order of magnitude as the observed uplift. The temporal evolution, however, is much different, with the uplift phase being longer than the observed uplift period, and the following subsidence much faster.

\section{CONCLUSION}

We presented some results of numerical simulations of hydrothermal circulation at the Phlegrean Fields, and of its effects on the mechanical behavior of porous rocks. The simulations confirm that periods of intense magmatic degassing induce important changes in the composition of the reservoir that feeds surface fumaroles. Such variations are associated with the different rate at which deep fluids are injected into the shallow hydrothermal system. Important variations also 
arise even if the composition of the injected mixture is unchanged. Gas composition appears to be controlled by the complex multi-phase and multi-component nature of this system. Recurring periods of more intense magmatic degassing may cause cumulative effects and also play a role in the compositional evolution of the fumarolic field. Coupled THM simulations showed that periods of higher injection rate can cause significant amounts of rock deformation. The pattern of simulated ground deformation matches the observed evolution, describing a fast uplift phase followed by slower subsidence. Simulations also confirm that maximum deformation is always attained at the end of the periods of more intense degassing, while peaks in gas composition are reached only afterwards, several months after the injection rate has been reduced again. If stronger magmatic degassing is to be considered one of the mechanism driving bradyseismic events, then the role of the geochemical signals as a precursor of system unrest should be carefully evaluated. More work is needed to better constrain rock properties and system conditions, but the proposed approach effectively captured many important features of the natural system and should represent a first step toward a robust assessment of the recent evolution at the Phlegrean Fields.

\section{ACKNOWLEDGEMENT}

The first author was financed by GNV (INGV) (Italy). The LBNL authors were supported by the Assistant Secretary for Energy Efficiency and Renewable Energy, Office of Geothermal Technologies, of the U.S. Department of Energy under contract No. DE-AC03-76SF00098.

\section{REFERENCES}

Allis, R.G., 2000. Review of subsidence at Wairakei field, New Zealand. Geothermics 29, 455478.

Allis, R.G., Zhan, X., 2000. Predicting subsidence at Wairakei and Ohaaku geothermal fields, New Zealand. Geothermics 29, 479-497.

Barberi, F., Corrado, G., Innocenti, F., Luongo, G., 1984. Phlegrean Fields 1982-1984: brief chronicle of a volcano emergency in a densely populated area. Bulletin of Volcanology 47, 175-185.

Bianchi, R., Corradini, A., Federico, C., Giberti, G., Lanciano, P., Pozzi, J.P., Sartoris, G., Scandone, R., 1987. Modelling of surface ground deformation in volcanic areas: the 19701972 and 1982-1984 crises of Campi Flegrei, Italy. Journal of Geophysical Research 92 (B13), 14139-14150.

Berrino, G., Corrado, G., Luongo, G., Toro, B., 1984. Ground deformation and gravity changes accompanying the 1982 Pozzuoli Uplift. Bulletin of Volcanology 47, 187-200. 
Bonafede, M., 1991. Hot fluid migration, an efficient source of ground deformation, application to the 1982-1985 crisis at Campi Flegrei-Italy. Journal of Volcanology and Geothermal Research 48, 187-198.

Bonafede, M., Dragoni, M., Quareni, F., 1986. Displacement and stress field produced by a centre of dilatation and by a pressure source in a viscoelastic half-space: application to the study of ground deformation and seismic activity at Campi Flegrei, Italy. Geophysical Journal of the Royal Astronomic Society 87, 455-485.

Caputo, M., 1979. Two thousands years of geodetic and geophysical observations in the Phlegrean Fields near Naples. Geophysical Journal of the Royal Astronomic Society 56, 319328.

Casertano, L., Olivieri del Castillo, A., Quagliariello, M.T., 1976. Hydrodynamics and geodynamics in the Phlegrean Fields area of Italy. Nature 264, 154-161.

Castagnolo, D., Gaeta, F.S., De Natale, G., Peluso, F., Mastrolorenzo, G., Troise, C., Pingue, F., Mita D.G., 2001. Campi Flegrei unrest episodes and possibile evolution towards critical phenomena. Journal of Volcanology and Geothermal Research 109, 13-30.

Chiodini, G., Marini L., 1998. Hydrothermal gas equilibria: the $\mathrm{H}_{2} \mathrm{O}-\mathrm{H}_{2}-\mathrm{CO}_{2}-\mathrm{CO}-\mathrm{CH}_{4}$ system. Geochimica e Cosmochimica Acta 62(15), 2673-2687.

Chiodini, G., Frondini, F., Cardellini, C., Granieri, D., Marini, L., Ventura, G., 2001. $\mathrm{CO}_{2}$ degassing and energy release at Solfatara Volcano, Campi Flegrei, Italy. Journal of Geophysical Research 106, 16213-16221.

Chiodini, G., Todesco, M., Caliro, S., Del Gaudio, C., Macedonio, G., Russo, M., 2003. Magma degassing as a trigger of bradyseismic events: The case of Phlegrean Fields (Italy). Geophysical Research Letters 30 (8), 1434-1437.

Cioni, R., Corazza, E., Marini, L., 1984. The gas/steam ratio as indicator of heat transfer at the Solfatara fumaroles, Phlegrean Fields (Italy). Bulletin of Volcanology 47, 295-302.

Corrado, G., Guerra, I., Lo Bascio, A., Luongo, G., Rampoldi, R., 1976. Inflation and microearthquacke activity of Phlegrean Fields, Italy. Bulletin of Volcanology 40, 169-188.

De Natale, G., Pingue, F., 1993. Ground deformation in collapsed caldera structures. Journal of Volcanology and Geothermal Research 57, 19-38.

De Natale, G., Petrazzuoli, S.M., Pingue, F., 1997. The effects of collapse structures on round deformation in calderas. Geophysical Research Letters 24(13), 1555-1558.

De Natale G., Troise C. and Pingue, F. (2001), A mechanical fluid-dynamical model for ground movements at Campi Flegrei caldera", Journal of Geodynamics, 32 (4-5), 487-517.

Dvorak, J.J., Berrino, G., 1991. Recent ground movement and seismic activity in Campi Flegrei, Southern Italy: episodic growth of a resurgent dome. Journal of Geophysical Research 96, 2309-2323.

Dvorak, J.J., Gasparini, P., 1991. History of earthquakes and vertical ground movement in Campi Flegrei caldera, Southern Italy; comparison of precursory events to the A.D. 1538 eruption of Monte Nuovo and of activity since 1968. Journal of Volcanological and Geothermal Research 48, 77-92. 
Dvorak, J.J., Mastrolorenzo, G., 1991. The mechanism of recent vertical crustal movements in Campi Flegrei caldera, Southern Italy. Geological Society of America, Special Paper 263, pp.47.

Dzurisin, D., Yamashita, K.M., 1987. Vertical surface displacement at Yellowstone caldera, Wyoming, 1976-1986. Journal of Geophysical Research 92 (B13), 13,753-13,766.

Dzurisin, D., Savage, J.C., Fournier, R.O., 1990. Recent crustal subsidence at Yellowstone Caldera, Wyoming. Bulletin of Volcanology 52, 247-270.

Dzurisin, D., Wicks, C. Thatcher, W., 1999. Renewed Uplift at the Yellowstone Caldera Measured by Leveling Surveys and Satellite Radar Interferometry, Bulletin of Volcanology 61, 349-355.

Gaeta, F.S., De Natale, G., Peluso, F., Mastrolorenzo, G., Castagnolo, D., Troise C., Pingue, F., Mita, D.G. and Rossano, S. Genesis and evolution of unrest episodes at Campi Flegrei caldera: the role of thermal-fluid-dynamical processes in the geothermal system. J. Geophys. Res. 103 (B9), 20921-20933, 1998.

Itasca Consulting Group Inc., 1997. FLAC3D Manual: Fast Lagrangian Analysis of Continua in 3 dimensions - Version 2.0. Itasca Consulting Group Inc., Minnesota, USA.

Marshall, G., Langbein, J., Stein, R. S., Lisowski, M., Svarc, J., 1997. Inflation of Long Valley Caldera, California, basin and range strain, and possible Mono craters dike inflation from 1990-94 GPS surveys, Geophysical Research Letters 24, 1003-1006.

Newhall, C.G., Dzurisin, D., 1988. Historical unrest at large calderas of the world, USGS bulletin 1855, 1108 .

Olivieri del Castillo, A., Quagliariello, M.T., 1969. Sulla genesi del bradisismo flegreo. Atti Associazione Geofisica Italiana, 18mo Congresso, Napoli, pp.557-594.

Orsi G., Petrazzuoli, S.M., Wohletz, K., 1999. Mechanical and thermo-fluid behaviour during unrest at the Campi Flegrei caldera (Italy). Journal of Volcanology and Geothermal Research 91, 453-470.

Pruess, K., 1991. TOUGH2 - A general purpose numerical simulator for multiphase fluid and heat flow. Report LBL 29400, Lawrence Berkeley National Laboratory, Berkeley, CA, USA.

Tedesco, D., Scarsi, P., 1999. Chemical (He, H2, CH4, Ne, Ar, N2) and isotopic (He, Ne, Ar, C) variations at the Solfatara crater (Southern Italy): mixing of different sources in relation to seismic activity. Earth and Planetary Science Letters 171, 465-480.

Todesco, M., Chiodini, G., Macedonio, G., 2003a. Monitoring and modeling hydrothermal fluid emission at La Solfatara (Phlegrean Fields, Italy). An interdisciplinary approach to the study of diffuse degassing. Journal of Volcanology and Geothermal Research, in press, 2003a.

Todesco, M., Rutqvist, J., Pruess, K., Oldenburg, C., 2003b. Multi-phase fluid circulation and ground deformation: a new perspective on bradyseismic activity at the Phlegrean Fields (Italy). Proceedings of the $28^{\text {th }}$ Workshop on Geothermal Research Engineering, Stanford, CA, USA.

Rutqvist, J., Wu, Y.-S., Tsang, C.-F., Bodvarsson, G., 2002. A modelling approach for analysis of coupled multiphase fluid flow, heat transfer, and deformation in fractured porous rock. International Journal of Rock Mechanics 39, 429-442. 
Tsang, C.-F., 1999. Linking thermal, hydrological, and mechanical processes in fractured rocks. Annual Review Earth and Planetary Sciences 27, 359-384.

Wicks, C., Thatcher, W., Dzurisin, D., 1998. Migration of fluids beneath Yellowstone Caldera inferred from satellite radar interferometry. Science 282, 458-462. 
Figure 1. The Phlegrean Fields caldera, with the location of Monte Nuovo and Solfatara eruptive centers. Lines indicate major collapse structures.

Figure 2. Computational domain for TOUGH2 simulations of hydrothermal fluid circulation. Boundary conditions and fluid source are indicated. Rock physical properties are also shown.

Figure 3. Initial conditions applied in each simulation. (a) Temperature $\left({ }^{\circ} \mathrm{C}\right)$ and (b) volumetric gas fraction resulting from a prolonged injection of hot water and carbon dioxide.

Figure 4. Measured (dots) and simulated (lines) compositional variations $\left(\mathrm{CO}_{2} / \mathrm{H}_{2} \mathrm{O}\right.$ vol) for simulation $3 x$, $5 x$ and $7 x$. Different lines refer to different simulations, as indicated. HIRPs and their duration (months) are highlighted.

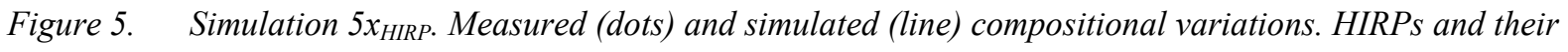
duration (months) are indicated.

Figure 6. Simulation 1x-C. Measured (dots) and simulated (line) compositional variations, with unchanged injection rates. Injected fluid composition changes during highlighted intervals (HIRP), as shown in Table 1.

Figure 7. Computational domain for the 3-D coupled simulations with TOUGH-FLAC, with boundary conditions and applied rock properties.

Figure 8. Simulation 10x: (a) Pressure (Pa), (b) temperature $\left({ }^{\circ} \mathrm{C}\right)$, (c) vol. gas fraction, and (d) $\mathrm{CO}_{2}$ mass fraction in gas, after 2 years of simulation (end of HIRP).

Figure 9. Simulation 10x (a) Pressure (Pa), (b) temperature $\left({ }^{\circ} \mathrm{C}\right)$, (c) vol. gas fraction, and (d) $\mathrm{CO}_{2}$ mass fraction in gas, 5 years after the injection rate has been reduced (7 years of simulation).

Figure 10. Simulation 10x-g (a) Pressure (Pa), (b) temperature $\left({ }^{\circ} \mathrm{C}\right)$, (c) vol. gas fraction, and (d) $\mathrm{CO}_{2}$ mass fraction in gas, 5 years after the injection rate has been gradually reduced (10 years of simulation)

Figure 11. Simulation 10x-l (a) Pressure (Pa), (b) temperature $\left({ }^{\circ} \mathrm{C}\right)$, (c) vol. gas fraction, and (d) $\mathrm{CO}_{2}$ mass fraction in gas 5 years after the injection rate has been reduced (15 yr of simulation).

Figure 12. Simulation 10x. Vertical ground displacement (m) (a) after 2 years of simulation (end of HIRP) and (b) after 7 years (5 years after the HIRP).

Figure 13. Simulation 10x-g. Vertical ground displacement $(m)(a)$ after 5 years of simulation (end of a HIRP) and (b) after 10 years (5 years after HIRP). 
Figure 14. Simulation 10x-l. Vertical ground displacement (m) (a) after10 years of simulation (end of HIRP) and (b) after 15 years (5 years after HIRP).

Figure 15. Maximum vertical ground displacement $(m)$ at the surface, for simulation $10 x$ (line), 10x-g (squares) and 10x-l (triangles)

Figure 16. Normalized maximum vertical displacement at the surface for simulation 10x (line) and measured data (points) 
Table 1. Input data for TOUGH2 hydrothermal fluid simulations. Injection rates refer to HIRP. Between different HIRP the injection rates are $1000 \mathrm{t} / d$ of $\mathrm{CO}_{2}$ and $2400 \mathrm{t} / \mathrm{d} \mathrm{H}_{2} \mathrm{O}$. Time intervals (months) of high injection rate are also shown.

\begin{tabular}{lccccccc}
\hline Name & $\mathrm{CO}_{2}(\mathrm{t} / \mathrm{d})$ & $\mathrm{H}_{2} \mathrm{O}(\mathrm{t} / \mathrm{d})$ & $\mathrm{CO}_{2} / \mathrm{H}_{2} \mathrm{Ov}$ & 1 st HIRP & 2nd HIRP & 3rd HIRP & 4th HIRP \\
\hline $3 \mathrm{x}$ & 3000 & 7200 & 0.17 & $0-19$ & $60-75$ & $126-136$ & $199-203$ \\
$5 \mathrm{x}$ & 5000 & 12000 & 0.17 & $0-19$ & $60-75$ & $126-136$ & $199-203$ \\
$7 \mathrm{x}$ & 7000 & 16800 & 0.17 & $0-19$ & $60-75$ & $126-136$ & $199-203$ \\
$5 \mathrm{x}_{\text {HIRP }}$ & 5000 & 12000 & 0.17 & $0-24$ & $55-75$ & $120-132$ & $199-203$ \\
$1 \mathrm{x}-\mathrm{C}$ & 1943 & 1457 & 0.30 & $0-19$ & $60-75$ & $126-136$ & $199-203$ \\
\hline
\end{tabular}

Table 2. Input data Coupled TOUGH-FLAC simulations.

\begin{tabular}{lccc}
\hline & $\mathrm{CO}_{2}(\mathrm{t} / \mathrm{d})$ & $\mathrm{H}_{2} \mathrm{O}(\mathrm{t} / \mathrm{d})$ & $\mathrm{CO}_{2} / \mathrm{H}_{2} \mathrm{O}(\mathrm{vol})$ \\
\hline HIRP & 15000 & 30000 & 0.2 \\
After HIRP & 1500 & 3000 & 0.2 \\
\hline Simulations & HIRP (yr) & Inj. Rate Reduction \\
\hline $10 \mathrm{x}$ & 2 & Sharp \\
$10 \mathrm{x}-\mathrm{g}$ & $2+3$ & Gradual (linear decrease after 2 years) \\
$10 \mathrm{x}-1$ & 10 & Sharp \\
\hline
\end{tabular}




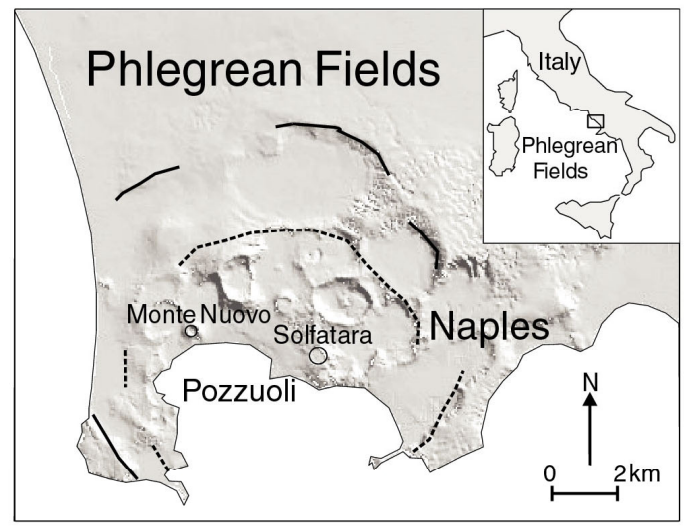

Figure 1 


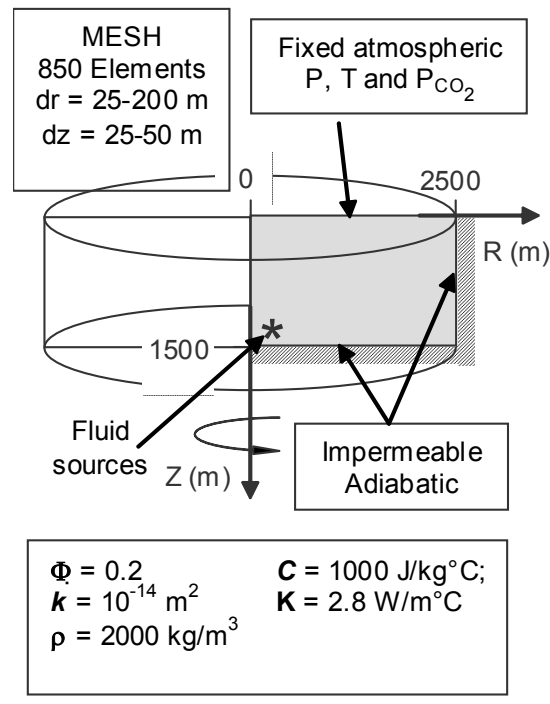

Figure 2 


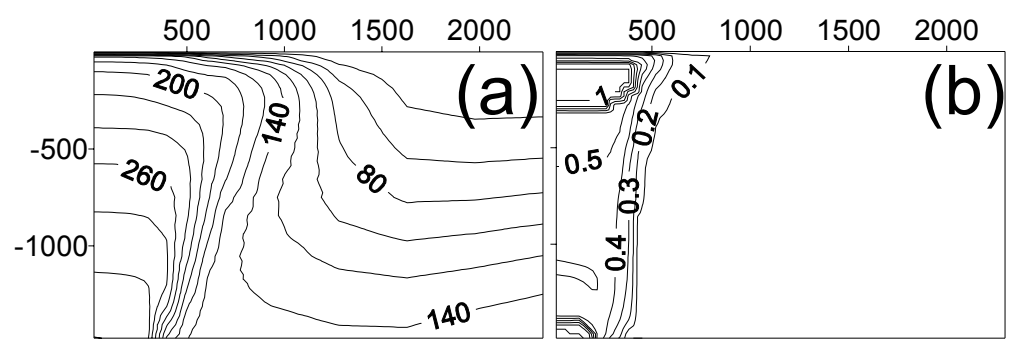

Figure 3 


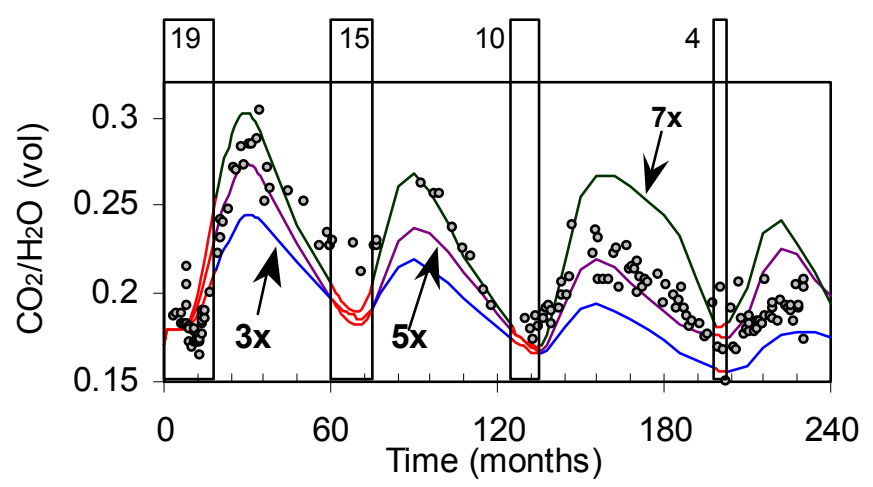

Figure 4. 


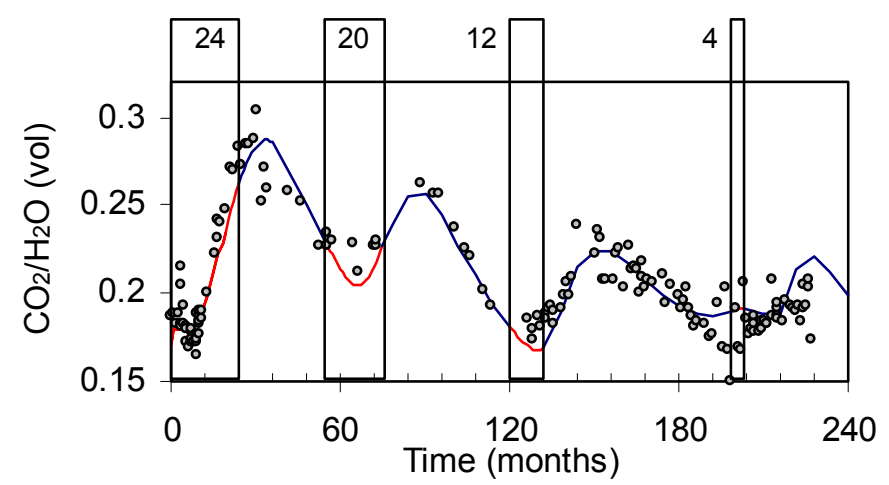

Figure 5. 


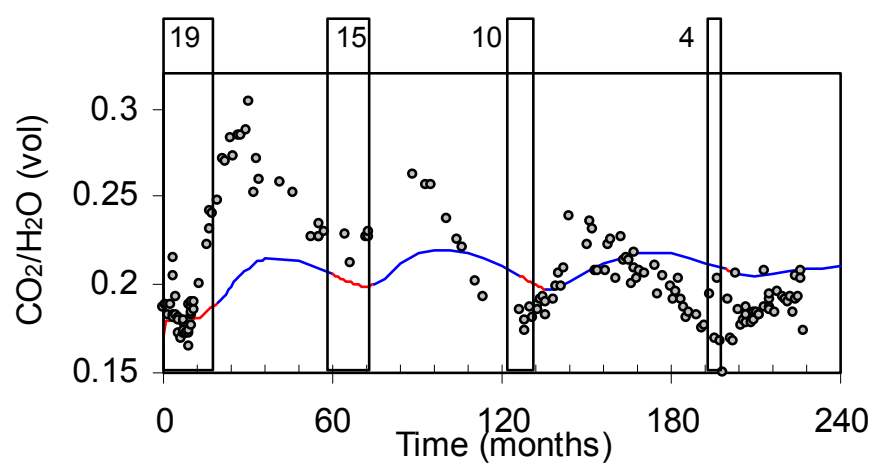

Figure 6 


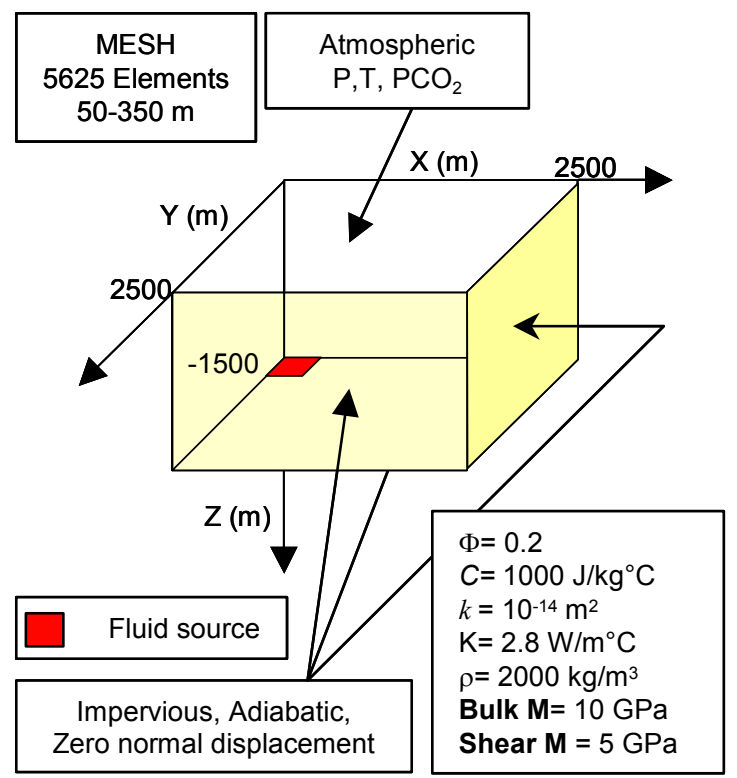

Figure 7. 


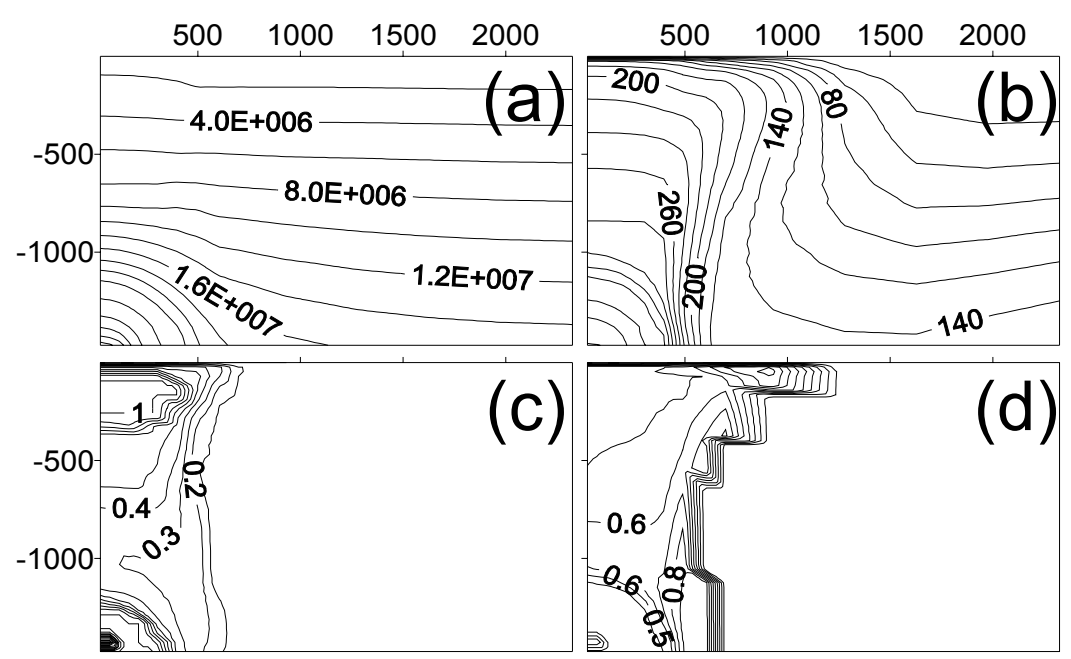

Figure 8. 


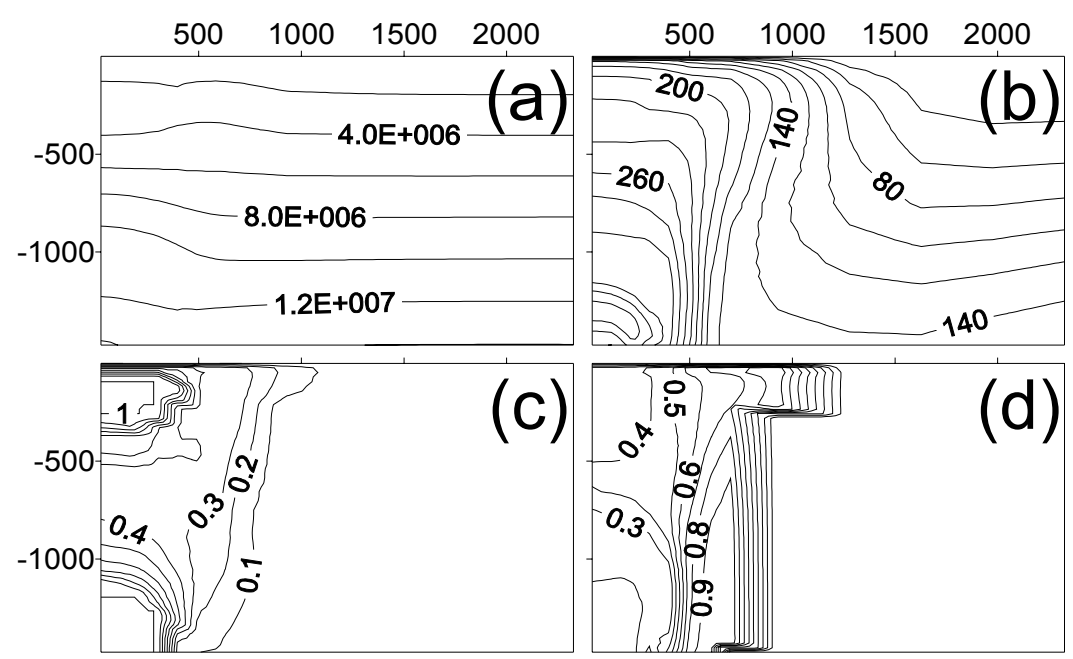

Figure 9. 


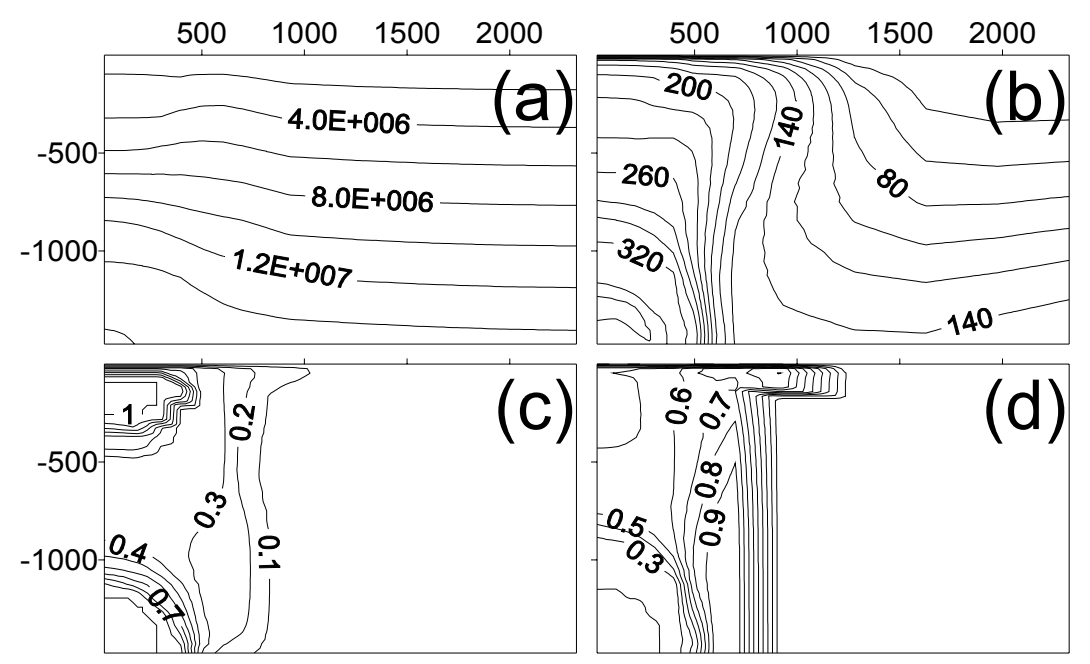

Figure 10. 


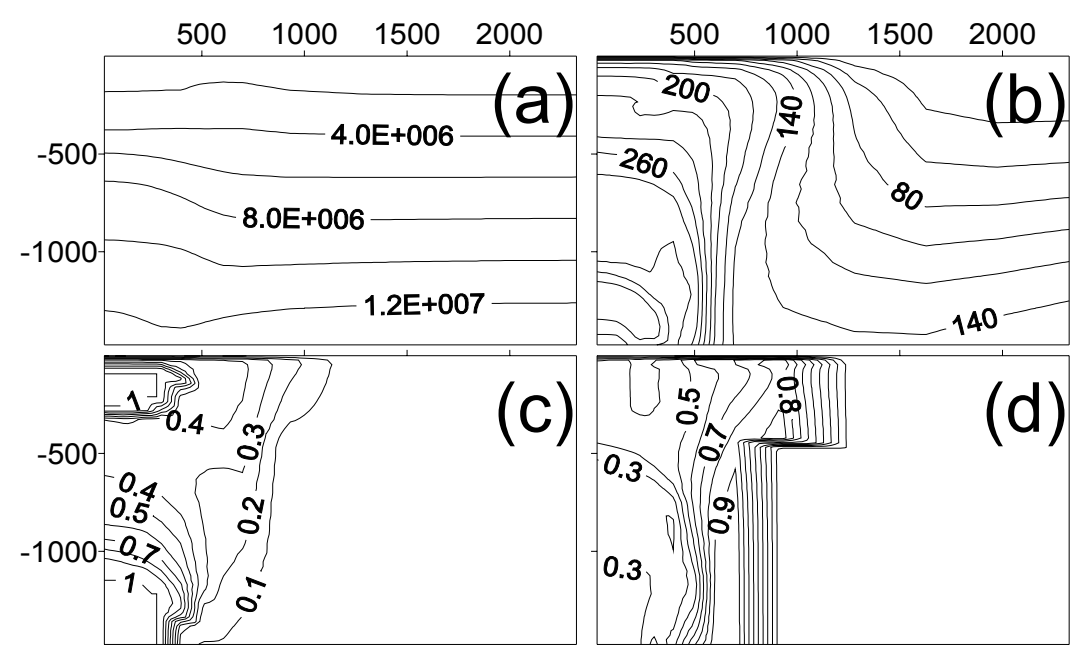

Figure 11. 


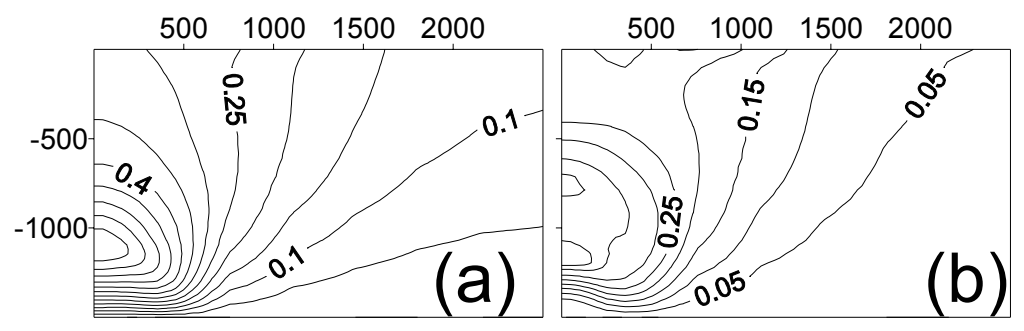

Figure 12. 


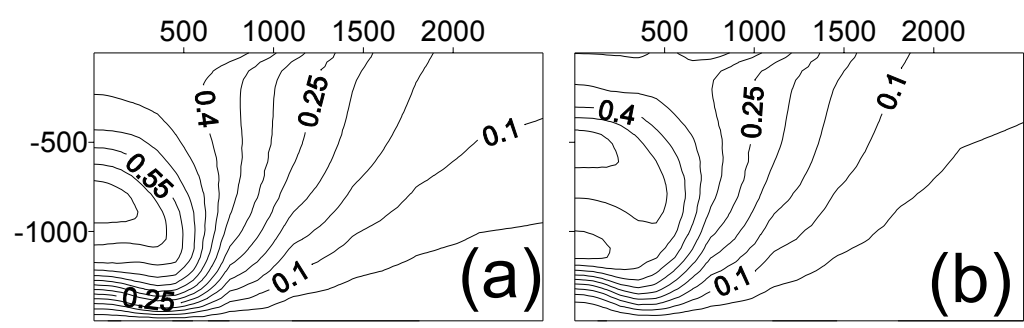

Figure 13. 


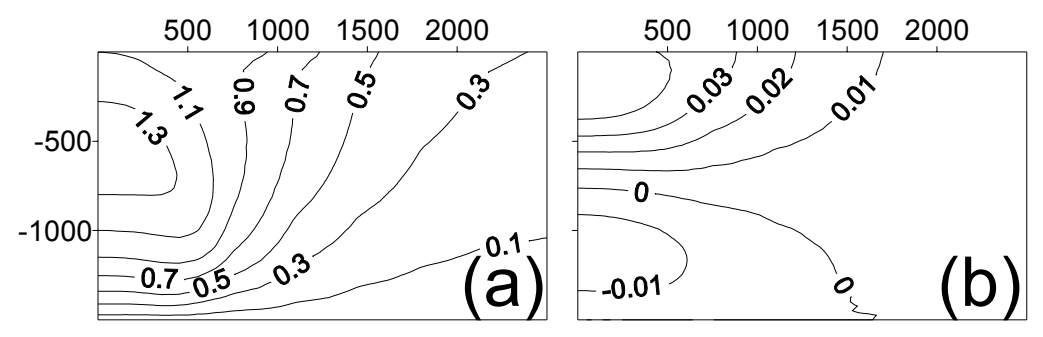

Figure 14. 


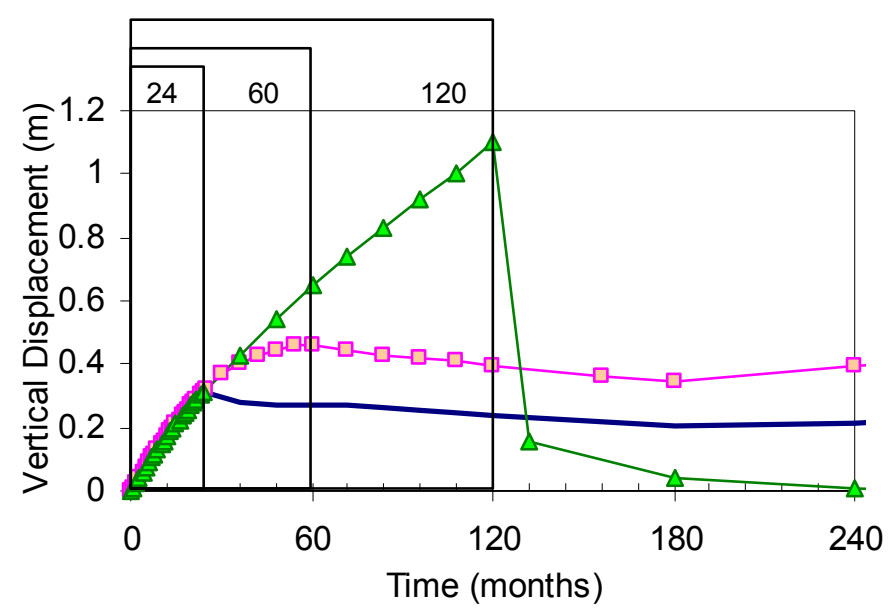

Figure 15. 


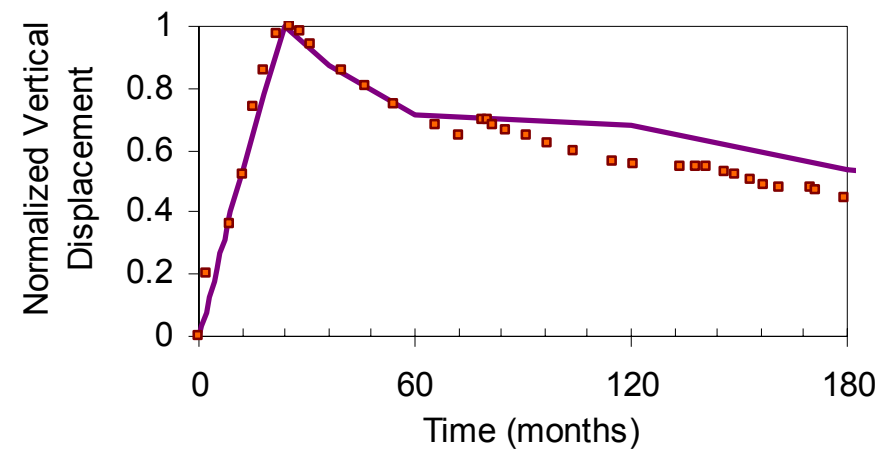

Figure 16 